\title{
Electrochemical and Theoretical Evaluation on the Corrosion Inhibition of Carbon Steel by Organic Selenides in Acidic Medium
}

\author{
Emad E. El-Katori ${ }^{1, *}$ and Yasser M. Al Angari ${ }^{2}$ \\ ${ }^{1}$ Department of Chemistry, Faculty of Science (New Valley), Assiut University, El-Kharja 72714, \\ Egypt \\ ${ }^{2}$ Department of Chemistry, Faculty of Science, King Abdul-Aziz University, Jeddah 21589, Saudi \\ Arabia \\ *E-mail: emad_992002@yahoo.com
}

doi: 10.20964/2018.05.05

Received: 6 January 2018 / Accepted: 26 February 2018 / Published: 10 April 2018

\begin{abstract}
The influence of organic solenoids as inhibitors for carbon steel (CS) dissolved in $1.0 \mathrm{M} \mathrm{HCl}$ had been tested via different electrochemical tests at 298K. Open circuit (OC), Tafel plots, electrochemical impedance spectroscopy (EIS) and electrochemical frequency modulation (EFM) tests had been examined. The gained data had been illustrated that organic selenides functioned as an effective and good inhibitors. The inhibition efficiency (IE\%) had been found to improve with improvement of inhibitor concentrations reaching maximum inhibition efficiency more than $80 \%$ at $298 \mathrm{~K}$. The Tafel plots had been illustrated that the organic selenides coordination were mixed type. The surface morphology of the carbon steel specimens in the absence and presence of organic solenoids had been evaluated by Scanning Electron Microscopy (SEM) and Atomic Force Microscopy (AFM) measurements. The influence of molecular structure on the inhibition efficiency (IE\%) has been investigated by quantum chemical computations. The relation between the inhibition efficiency and some quantum parameters have been evaluated and discussed.
\end{abstract}

Keywords: Organic selenides, $1.0 \mathrm{M} \mathrm{HCl}$, Corrosion, Carbon steel, Tafel plots, EIS, EFM, SEM, $\mathrm{AFM}, \mathrm{FMO}_{\mathrm{s}}$.

\section{FULL TEXT}

(C) 2018 The Authors. Published by ESG (www.electrochemsci.org). This article is an open access article distributed under the terms and conditions of the Creative Commons Attribution license (http://creativecommons.org/licenses/by/4.0/). 